\title{
TERAPIA COGNITIVO-COMPORTAMENTAL
}

\author{
Cognitive Beahavioral Therapy
}

\author{
Cloves Amorim ${ }^{1}$ \\ Marina Poniwas $^{2}$ \\ Léo PeruzzoJr. ${ }^{3}$
}

Sudak, D. M. (2008). Terapia cognitivo-comportamental na prática. Porto Alegre: Artmed.

"A terapia consiste, não em levar o paciente a descobrir a solução para o seu problema, mas em mudar o seu paciente de tal modo, que seja capaz de descobri-la".

(Skinner, 1967, p. 216)

$\mathrm{Na}$ prática docente e no exercício profissional, já contamos com excelentes manuais de terapia comportamental em língua portuguesa. Entretanto, as referidas obras: "Coleção sobre comportamento e cognição”, que já tem 19 volumes publicados; Rangé (1995); Rangé (2001); Ito (1998); Abreu e Roso (2002); Abreu e Guilhardi (2004); Salkovskis (2004); Mcmullin (2005); Leahy (2006); Dobson (2006); Cordioli (2007); para citar alguns, são úteis para o profissional já iniciado ou para os docentes.

A obra "Terapia cognitivo-comportamental na prática" vem preencher uma lacuna no que diz respeito aos primeiros passos nesta abordagem.

No Curso de Psicologia da PUCPR, no oitavo período, oferecemos a disciplina de "Laboratório de Práticas no Contexto Clínico". Neste Programa de Aprendizagem, estudamos casos clínicos e compartilhamos a formulação e o entendimento do caso em quatro abordagens: Psicologia Analítica, Psicodrama, Psicanálise e Psicologia Comportamental-Cognitiva. Cada professor da respectiva abordagem orienta o estudo de caso e a bibliografia para o grupo que está sob a sua supervisão. (Montenegro et al. 2004)

A obra de Donna Sudak foi recebida por nós como um presente para o desenvolvimento efetivo da aprendizagem neste laboratório.

Além da apresentação, a obra contém uma introdução, onde são relatados três casos clínicos. Em seguida, está subdividida em três seções e apêndices, totalizando 12 capítulos.

Psicólogo, Especialista em Didática do Ensino Superior e em Bioética, Doutorando em Psicologia, Docente do Curso de Psicologia da PUCPR e da FEPAR. Curitiba-PR. e-mail: cloves.amorim@pucpr.br

2 Acadêmica do nono período de Psicologia da PUCPR. Curitiba-PR. e-mail: madepol@ig.com.br

3 Mestrando em Filosofia pela PUCPR. Curitiba-PR. e-mail: peruzzo@yahoo.com.br 
A apresentação é iniciada por uma citação de Dobson (2002):

As terapias cognitivo-comportamentais são tratamentos relativamente de curta duração, voltadas para objetivos e focados em problemas que se baseiam fundamentalmente no modelo de que mudar as cognições é possível e leva a mudança comportamental.

Sudak informa que o objetivo do livro é "proporcionar uma visão geral e concisa das técnicas e da estrutura conceitual da terapia cognitivocomportamental; que o material foi organizado de modo a dar ao profissional iniciante uma visão geral de um tratamento bem documentado e efetivo para muitos transtornos psiquiátricos".

Ainda nas palavras de Sudak, "este livro foi projetado para facilitar o trabalho de clínicos iniciantes com seus pacientes usando terapia cognitiva". Conclui a introdução informando que o texto baseou-se na série de palestras para os residentes em Psiquiatria de Adultos da Faculdade de Medicina de Drexel University.

Três casos são apresentados na seção Introdução (são apresentadas as histórias do Sr. White, Sra. Green e Srta. Gray, eles são pacientes fictícios). O Sr. White é um estudante de pósgraduação em economia, de 45 anos. Apresenta sintomas de disforia, pouca energia e baixa autoestima. A Sra. Green é uma mulher casada, de 43 anos, que tem três filhas. Ela tem um longo histórico de ansiedade. E, por último, a Srta. Gray que é uma estudante de arte de 26 anos e tem histórico de tratamento psiquiátrico desde a adolescência.

A seção I - Fundamentos da Terapia Cognitiva apresenta três capítulos: 1) O desenvolvimento histórico da terapia cognitiva; 2) Modelo e Teoria cognitivos da psicopatologia; e 3) Formulação de Caso.

A seção II - O processo terapêutico e o relacionamento terapêutico na terapia cognitiva. Está composta por cinco capítulos: 4) O relacionamento entre o terapeuta e o paciente; 5) Ferramentas de tratamento; 6) Estruturas das seções; 7) Resistência; 8) Término.

A seção III apresenta Modelos Cognitivos de Transtornos Psicológicos: 9) Transtornos Afetivos; 10) Transtornos de Ansiedade; 11) Transtornos da Personalidade e terapia comportamental dialética; 12) Adesão à medicação.
Como posso me tornar um terapeuta cognitivo efetivo? E Diretrizes e exemplo de formulação de caso são dois apêndices.

De estrutura extremamente didática, cada capítulo explicita inicialmente os objetivos de aprendizagem e conclui com os pontos de Aprendizagem, seguidos das referências.

A redação é simples e objetiva, tratando com clareza os conceitos fundamentais e articulando com os três casos apresentados na Introdução. A Terapia Cognitiva conforme definida por Judith Beck (1997, p. 17) é o tratamento psicoperapêutico que tem o maior amparo empírico.

Em relação a tornar-se um terapeuta cognitivo efetivo, Sudak informa: é preciso muita prática, e acrescenta, à formação de qualquer terapeuta são necessários três elementos: aprendizagem didática, cuidados de pacientes e supervisão. Na página 154, a autora amplia seu posicionamento em relação à competência de terapeutas cognitivos e informa:

A primeira parte da aprendizagem para se tornar um terapeuta cognitivo envolve estabelecer as habilidades de relacionamento que são comuns a qualquer terapia e entender as demandas e os limites do encontro terapêutico. Os terapeutas devem ler e entender os princípios básicos do desenvolvimento humano e da Psicologia. Depois disso, aprendem as técnicas básicas da terapia cognitiva: a estruturação da seção, as ferramentas básicas do tratamento, os modelos para determinados transtornos e as primeiras habilidades para a conceituação. Integrar a conceituação e o tratamento já é um nível superior de habilidade, assim como adaptar os princípios básicos da terapia cognitiva para lidar com problemas mais complicados (Beck, 1997, p. 154).

Esperamos que esta obra possa responder aos questionamentos do aluno Moacir Lenzi, acadêmico do oitavo período do curso de Psicologia da PUCPR, quanto à psicopatologia e o relacionamento entre terapeuta e paciente na abordagem cognitiva. Também acreditamos que diferentes leitores, psiquiatras ou psicólogos possam ter o seu repertório ampliado quanto ao conhecimento da terapia cognitivo-comportamental. 


\section{Referências}

Abreu, C. N., \& GuilhardI, H. J. (Org.). (2004). Terapia comportamental e cognitivocomportamental: Práticas clínicas. São Paulo: Roca.

Abreu, C. N., \& Roso, M. (2002). As vertentes da Terapia Cognitiva. In: Jornal Mineiro de Psiquiatria, 17:13-15.

Beck, J. S. (1997). Terapia cognitiva: Teoria e prática. Porto Alegre: Artes Médicas.

Cordioli, A.V. (2007). TOC: Manual de terapia cognitivo-comportamental para 0 transtorno obsessivo-compulsivo. Porto Alegre: Artmed.

Dobson, K. S. (2006). Manual de terapias cognitivocomportamentais. Porto Alegre: Artmed.

Ito, L. M. (1998). Terapia cognitivo-comportamental para transtornos psiquiátricos. Porto Alegre:Artes Médicas.

McMullin, R. E. (2005). Manual de técnicas em terapia cognitiva. Porto Alegre: Artmed.

Montenegro, C. F., Amorim, C., Carvalho, J. Schimidt, M. Vicente, R. B., \& Mariotto, R. M. M. (2004). Professores Reflexivos e o Ensino de Psicoterapia. In Anais, 12. encontro nacional de didática e prática de ensino: Conhecimento local e conhecimento universal. Curitiba: PUCPR.

Rangé, B. (Org.). (1995). Psicoterapia comportamental e cognitiva de transtornos psiquiátricos. Campinas: Psy.

Rangé, B. (Org.). (2001). Psicoterapias cognitivocomportamentais: Um diálogo com a psiquiatria. Porto Alegre: Artmed.

Salkovskis, P. M. (2004). Fronteiras da terapia cognitiva. São Paulo: Casa do Psicólogo.

Recebido em: 24/10/2007

Received in: 10/24/2007

Aprovado em: 25/11/2007

Approved in: $11 / 25 / 2007$

Psicol. Argum., Curitiba, v. 25, n. 51, p. 427-429, out./dez. 2007 